PII: S0045-6535(98)00474-3

\title{
APPLICATION OF A SUPPORTED IRON OXYHYDROXIDE CATALYST IN OXIDATION OF BENZOIC ACID BY HYDROGEN PEROXIDE
}

\author{
Shanshan Chou* and Chihpin Huang** \\ Institute of Environmental Engineering, \\ National Chiao Tung University, Hsinchu, Taiwan, R.O.C. \\ (Received in Germany 6 July 1998; accepted 5 September 1998)
}

\begin{abstract}
Oxidation of benzoic acid was studied via Fenton-like reaction using an innovative supported $\gamma$-FeOOH catalyst. The decomposition kinetics of hydrogen peroxide was investigated first. Oxidation of benzoic acid by hydrogen peroxide was performed to understand the effects of initial $\mathrm{pH}$ and hydrogen peroxide dosage. The treatment efficiency of benzoic acid at an initial $\mathrm{pH}$ of 3.2 was higher than at initial $\mathrm{pHs}$ of 6.0 and 10.0; this can be partly explained by reductive dissolution of $\gamma-\mathrm{FeOOH}$. Therefore, the extent of heterogeneous catalysis was evaluated. We found that the majority of oxidation occurred on the catalyst surface, with some occurred in the solution due to iron dissolution of the catalyst. O1999 Elsevier Science Ltd. All rights reserved Key words: catalysis, iron oxide, oxidation, hydrogen peroxide
\end{abstract}

\section{INTRODUCTION}

Advanced oxidation processes (AOPs) show potential as one of the technologies for treating refractory compounds in waters and wastewaters. The combination of hydrogen peroxide and a ferrous salt has been referred to as "Fenton's reagent" (1). The primary oxidant in Fenton's reagent is the hydroxyl radical ( $\left.\mathrm{OH}_{0}\right)$ generated by the reaction of hydrogen peroxide with ferrous ion:

$$
\mathrm{H}_{2} \mathrm{O}_{2}+\mathrm{Fe}^{2+} \rightarrow \mathrm{OH} \cdot+\mathrm{OH}^{+}+\mathrm{Fe}^{3+}
$$

* Present address: Union Chemical Laboratories, ITRI, Hsinchu, Taiwan, R.O.C.

** To whom correspondence should be addressed. 
Oxidation of aromatics by the hydroxyl radical has been extensively investigated $(2,3)$. Fenton's reagent is an effective and simple oxidant of various types of organic contaminants. The drawback of Fenton's method for destruction of organics is the production of a significant amount of ferric hydroxide sludge that requires further separation and disposal.

Several authors have recently reported on the use of heterogeneous catalysts with hydrogen peroxide (4-7) and dissolved oxygen (8) as oxidants. Sandy aquifer material has been employed to study the decomposition kinetics of hydrogen peroxide and the degradation of quinoline (4). Goethite $(\alpha-\mathrm{FeOOH})$ particles have been used in the investigation of heterogeneous catalytic oxidation of $n$-butyl chloride by hydrogen peroxide (5). Lanstar High Force has developed a COE process (Catalytic Oxidation of Effluents) for the treatment of wastewater containing aromatic chemicals (6). This COE process uses a special catalyst to promote the oxidation reaction with hydrogen peroxide at $60^{\circ} \mathrm{C}$. In addition, a platinum-ruthenium catalyst on a carbon support was used in the oxidation of trichloroethylene at $130^{\circ} \mathrm{C}$ and 6 atm with dissolved molecular oxygen as the oxidant (8).

This study developed a novel supported iron oxide granular catalyst which is prepared via crystallization process. The easy solid-liquid separation of this catalyst after oxidation can conquer the disadvantage of Fenton's method. Benzoic acid is a common by-product of petrochemical and chemical processes. It was selected as the target organic compound for this study because of its non-volatility, aromatic structure, and high reactivity with $\mathrm{OH}$. but slow oxidation by hydrogen peroxide. The effects of $\mathrm{pH}$ and the hydrogen peroxide dosage on removal of benzoic acid by hydrogen peroxide were investigated. The performance of this novel catalyst and other iron oxide catalysts were also compared.

\section{EXPERIMENTAL}

\subsection{Catalyst preparation}

A novel granular catalyst, with the iron oxide on a brick grain support, was developed in this research in the following manner. The brick granular particles, purchased from a brick - processing factory in Taiwan, were packed as carriers in a 6.1 liter $(6.8 \mathrm{~cm}-\phi \times 170 \mathrm{~cm}-\mathrm{H})$ fluidized bed reactor. $\mathrm{H}_{2} \mathrm{O}_{2}$ (Union Chemical Works Ltd.) and $\mathrm{FeSO}_{4}$ (Merck) were fed continuously with molar ratio of 1:2 into the reactor bottom and the crystals were allowed to grow on the surface of brick particles for one week. The $\mathrm{pH}$ of the solution was controlled at 3.5 to prevent $\mathrm{Fe}(\mathrm{OH})_{3}$ precipitation. The color of brick granular particles changed from orange to reddish purple after crystallization. The crystallized particles, in which via crystallization in the fluidized bed one week (9), were harvested from the fluidized bed to analyze the catalyst characteristics.

\subsection{Analytical methods and catalyst characterization}

Hydrogen peroxide and benzoic acid were analyzed using HPLC with a reverse phase Merck 
LiChrospher C-18 column ( $25 \mathrm{~cm}-\mathrm{L} \times 4 \mathrm{~mm}-$ ID) on the mobile phase of $40 \%$ methanol (Fisher) and $60 \%$ deionized water containing tetra-n-butylammonium phosphate PICA reagent (paired ion chromatography reagent for acid, TCI). Total iron concentration was determined with an atomic absorbance spectrophotometer (Varian Spectra AA-30). Dissolved organic carbon (DOC) was determined using a TOC analyzer (Dohrmann DC-190). The specific surface area, average pore size, and total pore volume were measured by a $\mathrm{N}_{2}$-BET meter (Micromeritics ASAP 2400). The average particle size and the shape factor were determined using an image analyzer (Galai ScanArray-2 series). The iron content of the catalyst was dissolved via digestion treatment and analyzed using an inductively coupled plasma emission spectroscopy (ICP, ARL 3580). The granular catalyst was identified using a Mössbauer spectrometer (Austin S-600) (10); ${ }^{57} \mathrm{Co}(\mathrm{Pd})$ was used as the source and iron foil was used as the standard for the isomer shift.

\subsection{Experimental procedures}

Experiments were conducted at room temperature. The agitation mixing of batch reactors was kept at $120 \mathrm{rpm}$. The batch reactor was prepared by filling with the proper amount of the granular catalyst $(10 \mathrm{~g} / 1 \mathrm{or}$ $20 \mathrm{~g} / \mathrm{l})$ and $500 \mathrm{ml}$ of benzoic acid solution, $\mathrm{pH}$ was then adjusted to the desired initial value. Concentrated hydrogen peroxide $(10 \% \mathrm{w} / \mathrm{v})$ was added continuously within the first five minutes of the reaction at a rate depending on the desired dosage. For the experiments in section 3.4, the dosage of hydrogen peroxide was varied from $200 \mathrm{mg} / \mathrm{l}$ to $1600 \mathrm{mg} / \mathrm{l}$. For the rest of the experiments, the dosage of hydrogen peroxide was $800 \mathrm{mg} / \mathrm{l}$. The initial concentration of benzoic acid ranged from $107 \mathrm{mg} / \mathrm{l}$ to $116 \mathrm{mg} / \mathrm{l}$ in the studies of oxidation. The supernatant was filtered for the analyses of $\mathrm{H}_{2} \mathrm{O}_{2}$, DOC, iron, and benzoic acid.

\section{Results and discussion}

\subsection{Catalyst characterization}

Table 1 lists the properties of the carrier and the novel granular catalyst produced from the fluidized bed crystallization reactor. The iron contents of original brick grain (carrier) and crystallized brick grain (catalyst) were 40.6 and $135.1 \mathrm{~g} / \mathrm{kg}$, respectively. After crystallization, the average pore size reduced but the total pore volume increased apparently, resulting in a higher overall porosity. The carriers (i.e., supports) consist mainly of quartz $\left(\mathrm{SiO}_{2}\right)$ according to XRD; the minor component, $\alpha-\mathrm{Fe}_{2} \mathrm{O}_{3}$, was found in the Mössbauer spectrum (Figure 1a). Figure lb shows the Mössbauer spectrum of the granular catalyst at roomtemperature. The central quadrupole doublet represents $\gamma$-FeOOH. The isomer shift and quadrupole splitting of Mössbauer parameters were 0.36 and 0.69 , respectively. Therefore, the major component coated on the catalyst surface was determined to be $\gamma-\mathrm{FeOOH}(10) . \gamma-\mathrm{FeOOH}$ (also called lepidocrocite) has been identified as the first solid product of corrosion, and it can convert into $\alpha-\mathrm{FeOOH}$, and later, $\gamma-\mathrm{Fe}_{2} \mathrm{O}_{3}(10)$. After crystallization, the average brick grain surface area increased from $2.57 \mathrm{~m}^{2} / \mathrm{g}$ to $48.3 \mathrm{~m}^{2} / \mathrm{g}$, which is 
relatively lower than the surface area of pure $\mathrm{FeOOH}\left(164.1 \mathrm{~m}^{2} / \mathrm{g}\right.$, Aldrich). The synthesis of $\gamma$-FeOOH may occur via the oxidation of ferrous ion by hydrogen peroxide $(11,12)$ as below:

$$
\mathrm{H}_{2} \mathrm{O}_{2}+2 \mathrm{Fe}^{2+}+2 \mathrm{H}_{2} \mathrm{O} \longrightarrow 2 \gamma-\mathrm{FeOOH}+4 \mathrm{H}^{+}
$$

By means of shaking tests, we found that the coating of $\gamma-\mathrm{FeOOH}$ on the brick grain carrier is much stronger than that on silica sand, another common carrier (seed). Under the same crystallization condition for one week, the iron content of $\gamma$-FeOOH-laden silica sand was determined to be $59.1 \mathrm{~g} / \mathrm{kg}$ by ICP, which is significantly lower than that of $\gamma-\mathrm{FeOOH}$-laden brick grains $(135.1 \mathrm{~g} / \mathrm{kg})$ as listed in Table 1 . The iron constituent in brick grains is considered to be the major factor in prompting crystal growth, as well as the formation of delicate crystal structures.

Table 1. Properties of the carrier and the catalyst produced from the fluidized bed crystallization reactor

\begin{tabular}{ccc}
\hline Parameters & $\begin{array}{c}\text { Carrier } \\
\text { (original brick grain) }\end{array}$ & $\begin{array}{c}\text { Catalyst } \\
\text { (crystallized brick grain) }\end{array}$ \\
\hline Iron content $(\mathrm{g} / \mathrm{kg})$ & 40.6 & 135.1 \\
Bulk density $\left(\mathrm{g} / \mathrm{cm}^{3}\right)$ & 1.010 & 1.111 \\
Average particle size $(\mathrm{mm})$ & 0.515 & 0.564 \\
Specific surface area $\left(\mathrm{m}^{2} / \mathrm{g}\right)$ & 2.57 & 48.3 \\
Average pore size $(\mu \mathrm{m})$ & 0.0079 & 0.0036 \\
Total pore volume $\left(\mathrm{cm}^{3} / \mathrm{g}\right)$ & 0.0051 & 0.0431 \\
Shape factor & 0.769 & 0.804 \\
\hline
\end{tabular}

\subsection{Decomposition of hydrogen peroxide in the absence of benzoic acid}

The reaction of hydrogen peroxide with metals or metal oxides is usually described by a modified Haber-Weiss mechanism as below (13):

$$
\mathrm{H}_{2} \mathrm{O}_{2}+\mathrm{S} \rightarrow \mathrm{OH}_{\bullet}+\mathrm{OH}^{+}+\mathrm{S}^{+}
$$

where $S$ denotes the active site on the catalyst surface and $\mathrm{S}^{+}$represents the oxidized site. In the absence of benzoic acid, the decomposition rate of hydrogen peroxide follows a first-order relationship with the concentration of hydrogen peroxide in this heterogeneous catalysis system:

$$
-\frac{d\left[\mathrm{H}_{2} \mathrm{O}_{2}\right]}{d t}=k_{o b s}\left[\mathrm{H}_{2} \mathrm{O}_{2}\right]
$$

Equation (4) can be transformed into an integrated expression,

$$
\ln \frac{\left[\mathrm{H}_{2} \mathrm{O}_{2}\right]}{\left[\mathrm{H}_{2} \mathrm{O}_{2}\right]_{i}}=-k_{o b s} \times t
$$


where $t$ denotes the reaction time, $\left[H, O_{3}\right]_{i}$ and $\left[H, O_{2}\right]$ represent the hydrogen peroxide concentrations at the initial stage and at a specific reaction time, and $k_{\infty}$ is an observed first-order rate constant.
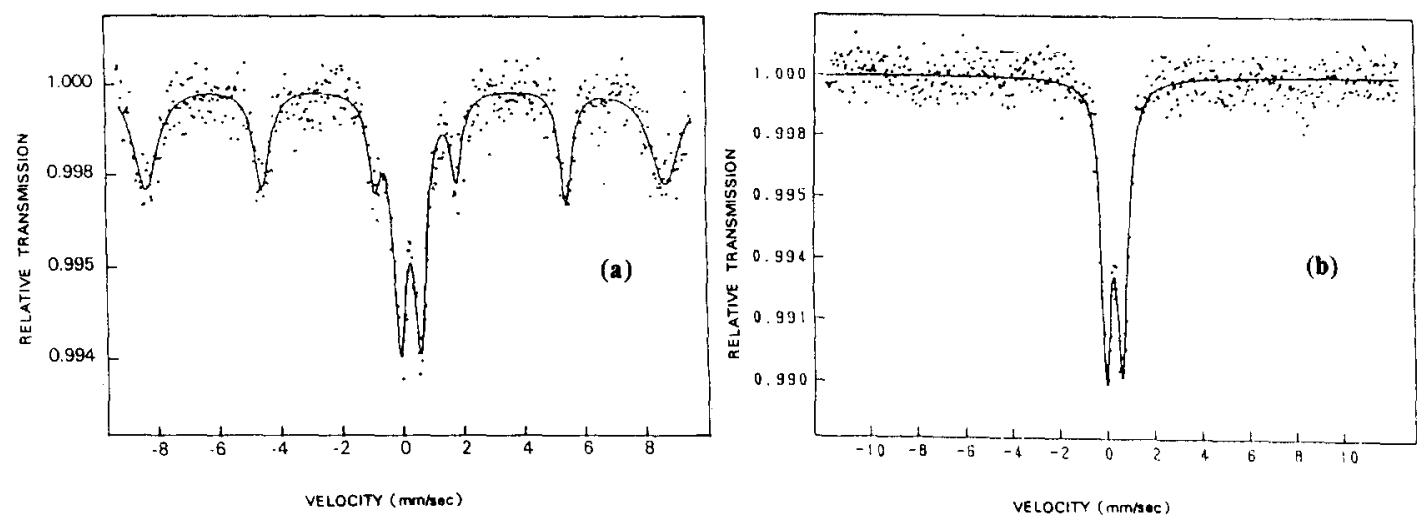

Figure 1. Room-temperature Mössbauer spectrum of (a) the carrier, and.(b) the granular catalyst produced from the fluidized bed crystallization reactor.

In Table 2, the effect of initial $\mathrm{pH}$ (designated as $\mathrm{pHi}$ ) on hydrogen peroxide decomposition in the absence of organic compounds is summarized. It is evident that the decomposition rate was strongly $\mathrm{pH}$ dependent, and appeared to increase as $\mathrm{pH}$ increased in this heterogeneous catalysis, which was also observed in the goethite system (5). According to the surface complexation theory, when $\mathrm{pH}$ is changed, the binding strength between hydrogen peroxide and iron oxyhydroxide may be altered due to the different distribution of three surface species ( $\equiv \mathrm{Fe}^{\mathrm{III}}-\mathrm{OH}_{2}{ }^{+}, \equiv \mathrm{Fe}^{\mathrm{III}}-\mathrm{OH}$, and $\left.\equiv \mathrm{Fe}^{\mathrm{III}}-\mathrm{O}^{-}\right)(14,15)$. The results demonstrate that hydrogen peroxide may favor the more negatively charged oxide surface, which can be explained by the conclusion of Wallace (16) that hydrogen peroxide may form strong complexes with compounds possessing weak base properties.

Table 2. Effect of initial $\mathrm{pH}$ on hydrogen peroxide decomposition

\begin{tabular}{cc}
\hline $\mathrm{pHi}$ & $\mathrm{k}_{\mathrm{obs}}\left(\mathrm{hr}^{-1}\right)$ \\
\hline 3.3 & 0.102 \\
5.4 & 0.123 \\
7.0 & 0.272 \\
8.9 & 0.326 \\
\hline
\end{tabular}

$\left[\mathrm{H}_{2} \mathrm{O}_{2}\right]_{i}=800 \mathrm{mg} / \mathrm{l}$, catalyst concentration $=20 \mathrm{~g} / \mathrm{l}$

\subsection{Effects of $\mathrm{pH}$ on oxidation of benzoic acid by hydrogen peroxide}

Figures $2 \mathrm{a}$ and $2 \mathrm{~b}$ display the effects of initial $\mathrm{pH}$ on the percentage of benzoic acid remaining after oxidation $\left(\mathrm{BA} / \mathrm{BA}_{\mathrm{i}}\right)$ and the dissolved iron concentration, respectively. The amount of the catalyst used in 
these experiments was $10 \mathrm{~g} / 1$. After 6 hours of reaction, the final $\mathrm{pH}$ values of the reactors changed to 3.0 , 4.3 and 5.8 from initial $\mathrm{pH}$ values of $3.2,6.0$ and 10.0 , respectively. In the absence of hydrogen peroxide, only trace amount of benzoic acid was adsorbed on the granular catalyst at the equilibrium $\mathrm{pH}$ of 5.0 (pHi 6.0 ) and 6.5 (pHi 10.0), in contrast to about $11 \%$ when equilibrium $\mathrm{pH}$ was 3.2 (pHi 3.2). The stronger adsorption at low $\mathrm{pH}$ may be attributed to the low pKa of benzoic acid (i.e., $\mathrm{pKa}=4.2$ ). According to the $\mathrm{pHzpc}$ (point of zero charge) of $\gamma-\mathrm{FeOOH}$ (i.e., pHzpc $=7.2)(17)$, the catalyst carried a positive charge between $\mathrm{pH} 3.2$ and 7.2. Adsorption of benzoic acid on the catalyst is pH-dependent, as has been commonly observed in the study of simple organic acids adsorption on iron oxide $(18,19)$.

Figure 2a depicts that the benzoic acid oxidation rate at pHi 3.2 exceeds those at $\mathrm{pHi} 6.0$ and 10.0 . The higher benzoic acid oxidation rate at pHi 3.2 may correlate to the adsorption behavior of benzoic acid on the granular catalyst. This was also in accordance with the following phenomena: the dissolved iron concentration increased from $1.4 \mathrm{mg} / \mathrm{l}$ to $4.3 \mathrm{mg} / \mathrm{l}$ between $3 \mathrm{~h}$ and $6 \mathrm{~h}$ at $\mathrm{pHi} 3.2$, but was below $0.15 \mathrm{mg} / \mathrm{l}$ at pHi 6.0 and 10.0, as shown in Figure 2b. This was due to the reductive dissolution reaction of $\gamma$ - $\mathrm{FeOOH}$ as described below $(10,15,20)$ :

$$
\gamma-\mathrm{FeOOH}_{(s)}+3 \mathrm{H}^{+}+\mathrm{e}^{-} \rightarrow \mathrm{Fe}^{2+}+2 \mathrm{H}_{2} \mathrm{O}
$$

Stone (20) found that the rate of reductive dissolution was dependent on $\mathrm{pH}$ and organic reductant concentration. Therefore, the acidic condition favors reductive dissolution of $\gamma$-FeOOH which may increase the initial rate of Fenton's reaction. From the above results, we may conclude that the reaction of $\mathrm{OH}$ radicals with benzoic acid occurs not only on the catalyst surface, but also in the aqueous solution (Fenton's reaction) through iron dissolution of the catalyst at pHi 3.2 .

\subsection{Effect of hydrogen peroxide dosage on axidation of benzoic acid and reductive dissolution of iron oxyhydroxide}

The influence of hydrogen peroxide dosage on oxidation of benzoic acid was also investigated. The change of dissolved iron during the reaction was shown in Figure 3a. The result indicates that there was an obvious difference in iron concentrations depending on the dosage of $\mathrm{H}_{2} \mathrm{O}_{2}$. They also show that the presence of benzoic acid affected the iron concentration. The dissolved iron concentration increased with increasing $\mathrm{H}_{2} \mathrm{O}_{2}$ dosage in the presence of benzoic acid. Without benzoic acid (the control test), the dissolved iron in the aqueous phase increased only slightly to approximately $0.25 \mathrm{mg} / \mathrm{l}$ even after 6.5 hours of reaction time at dosages from 200 to $1600 \mathrm{mg} / \mathrm{l} \mathrm{H}_{2} \mathrm{O}_{2}$. Thus, the dissolved iron contributed only trivial effect to the decomposition of $\mathrm{H}_{2} \mathrm{O}_{2}$. This finding also correlates with the reductive dissolution of $\gamma-\mathrm{FeOOH}$, as indicated in equation (6). Benzoic acid adsorbed on the iron oxyhydroxide surface can readily exchange electrons with an Fe(III) surface center, and can form inner-sphere surface complexes (15). Heterogeneous catalytic oxidation of benzoic acid donates electrons to enhance $\mathrm{Fe}^{2+}$ dissolution of $\gamma$-FeOOH under acidic conditions, which induces the homogeneous catalytic oxidation. Therefore, we can conclude that 

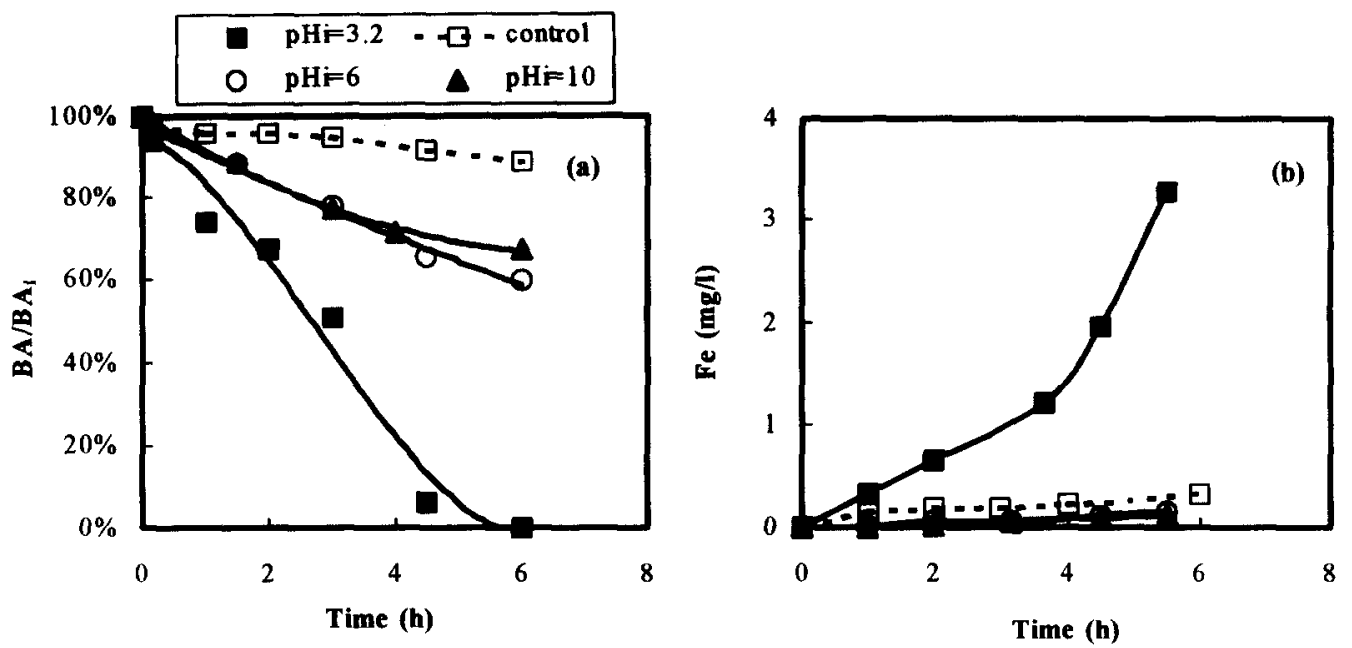

Figure 2. Effects of initial pH values on (a) the benzoic acid remaining percentage, and (b) the dissolved iron concentration in oxidation of benzoic acid. The control experiment is conducted in the absence of $\mathrm{H}_{2} \mathrm{O}_{2}$ with pHi 3.2 for adsorption alone. $\left[\mathrm{H}_{2} \mathrm{O}_{2}\right]_{i}=800 \mathrm{mg} / \mathrm{l}$, [catalyst] $=10 \mathrm{~g} / \mathrm{l},[B A]_{i}=116 \mathrm{mg} / \mathrm{l}$, [catalyst $]$ denotes the catalyst concentration
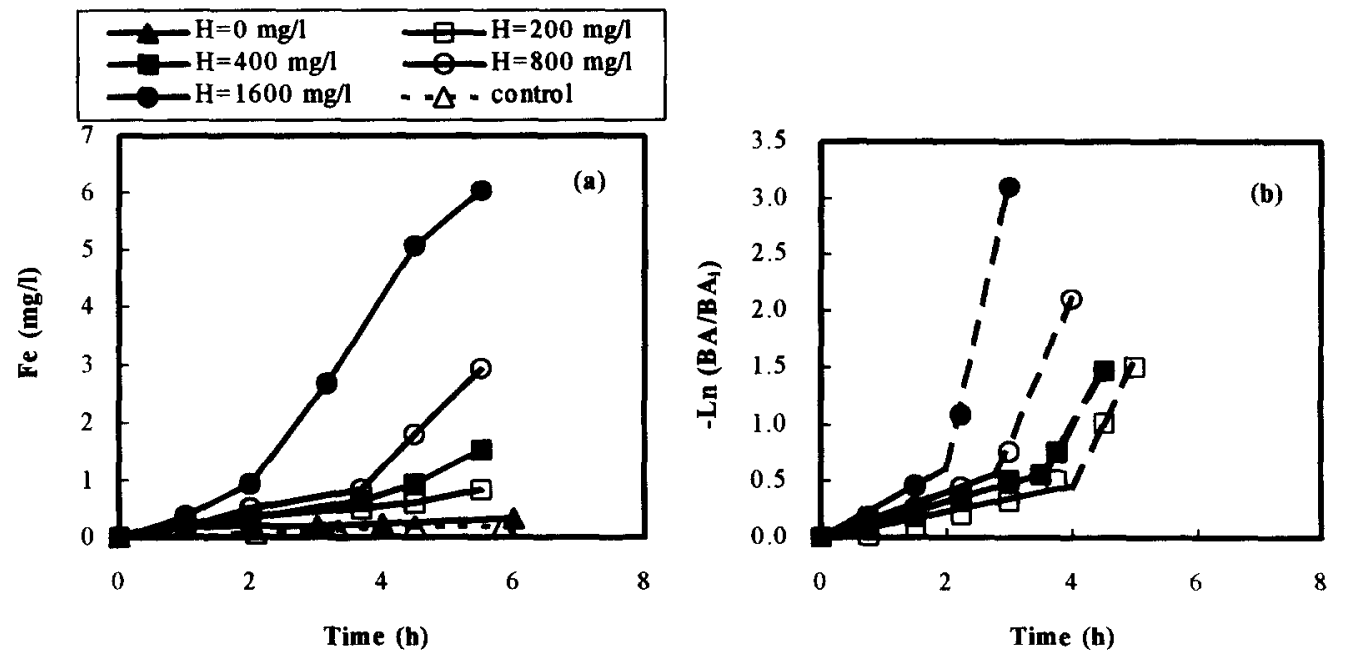

Figure 3. Effects of hydrogen peroxide dosages on (a) dissolved iron concentrations, and (b) the two-stage, first-order reaction kinetics in oxidation of benzoic acid. The control experiment is conducted in the absence of benzoic acid with $\mathrm{H}_{2} \mathrm{O}_{2}$ dosage of $1600 \mathrm{mg} / \mathrm{l}$ pHi=3.2, [catalyst] $=20 \mathrm{~g} / \mathrm{l},[B A]_{i}=107 \mathrm{mg} /, \mathrm{H}$ denotes $\mathrm{H}_{2} \mathrm{O}_{2}$ dosage 
heterogeneous and homogeneous oxidation reactions are closely related.

To analyze the kinetics of benzoic acid degradation, the plots of $-\ln (\mathrm{BA} / \mathrm{BA})$ vs. time is presented in Figure $3 \mathrm{~b}$. The two-stage first-order reaction kinetics describes the change of benzoic acid reasonably well. As shown in Figure $3 \mathrm{~b}$, the turning points of the four curves all occurs at $0.5-1.0 \mathrm{mg} / 1$ of dissolved iron concentration. The first stage has a lower reaction rate constant because heterogeneous catalysis dominates here, which will be verified in section 3.6. The higher reaction rate constant occurring in the second stage is attributed to reductive dissolution of iron oxyhydroxide, which corresponds to Figure $3 \mathrm{a}$.

\subsection{Comparison of supported $\curlyvee \mathrm{FeOOH}$ catalyst with other iron oxide catalysts}

To compare the performance of this novel catalyst with other iron oxide catalysts $(5,21,22)$, we evaluated two indexes: the stoichiometric efficiency (E) in oxidizing pollutants by $\mathrm{H}_{2} \mathrm{O}_{2}$, and the $\mathrm{H}_{2} \mathrm{O}_{2}$ decomposition rate constant $\left(\mathbf{k}_{\text {surf }}\right)$ in the absence of pollutants (Table 3$)$. We define $\mathrm{E}$ as below (21):

$$
\mathrm{E}(\text { mole } / \text { mole })=\frac{\Delta[\text { pollutant }]}{\Delta\left[\mathrm{H}_{2} \mathrm{O}_{2}\right]}
$$

When $\mathrm{E}$ is low, few radicals react with organic compounds, instead they undergo inefficient scavenging reaction (21). Furthermore, $\mathrm{E}$ is affected by the type and concentration of the pollutant, $\mathrm{H}_{2} \mathrm{O}_{2}$ concentration, and $\mathrm{pH}(4,21,22)$. The normalized rate constant to the surface area, $\mathbf{k}_{\text {surf }}$ is defined as below:

$$
\mathrm{k}_{\mathrm{surf}}=\frac{\mathrm{kobs}}{\text { (catalyst surface area per liter of water) }}
$$

Valentine and Wang (21) have demonstrated that oxides could have similar reactivity, but different catalytic activity for organic compounds. All three oxides exhibited similar reactivities toward $\mathrm{H}_{2} \mathrm{O}_{2}$ decomposition $\left(\mathrm{k}_{\text {sur }}\right)$, however, the stoichiometric efficiencies of ferrihydrite and semicrystalline were only $14 \%$ and $43 \%$, respectively, compared with that of goethite (Table 3 ). This may be due to their structural difference; ferrihydrite has more vacant $\mathrm{Fe}$ sites and $\mathrm{OH}$ groups to consume radicals than goethite (23). As shown in Table 3, among these oxides studied in the reviewed literatures, goethite possesses the highest catalytic activity. Therefore, we compared the supported $\gamma$-FeOOH catalyst prepared in our laboratory with the purchased goethite granular particle. The catalytic activity of the supported $\gamma-\mathrm{FeOOH}$ catalyst was also evaluated with another refractory target compound, 2,4,6-trichlorophenol (Table 3). The results indicate that the novel catalyst had lower $k_{\text {sur }}$ but higher $\mathrm{E}$ than goethite. It proves that the novel granular catalyst is promising because of the insignificant $\mathrm{OH}_{0}$ scavenging behavior.

In our study, the $\mathrm{E}$ value in treating benzoic acid decreased to a plateau when $\mathrm{pH}$ increased to 4.3 , which is similar to the result of Khan and Watts (22). Figure $3 \mathrm{~b}$ and Table 3 indicate that higher $\mathrm{H}_{2} \mathrm{O}_{2}$ dosages induce faster benzoic acid degradation, yet reduce $\mathrm{E}$. These phenomena may be due to the competition of 


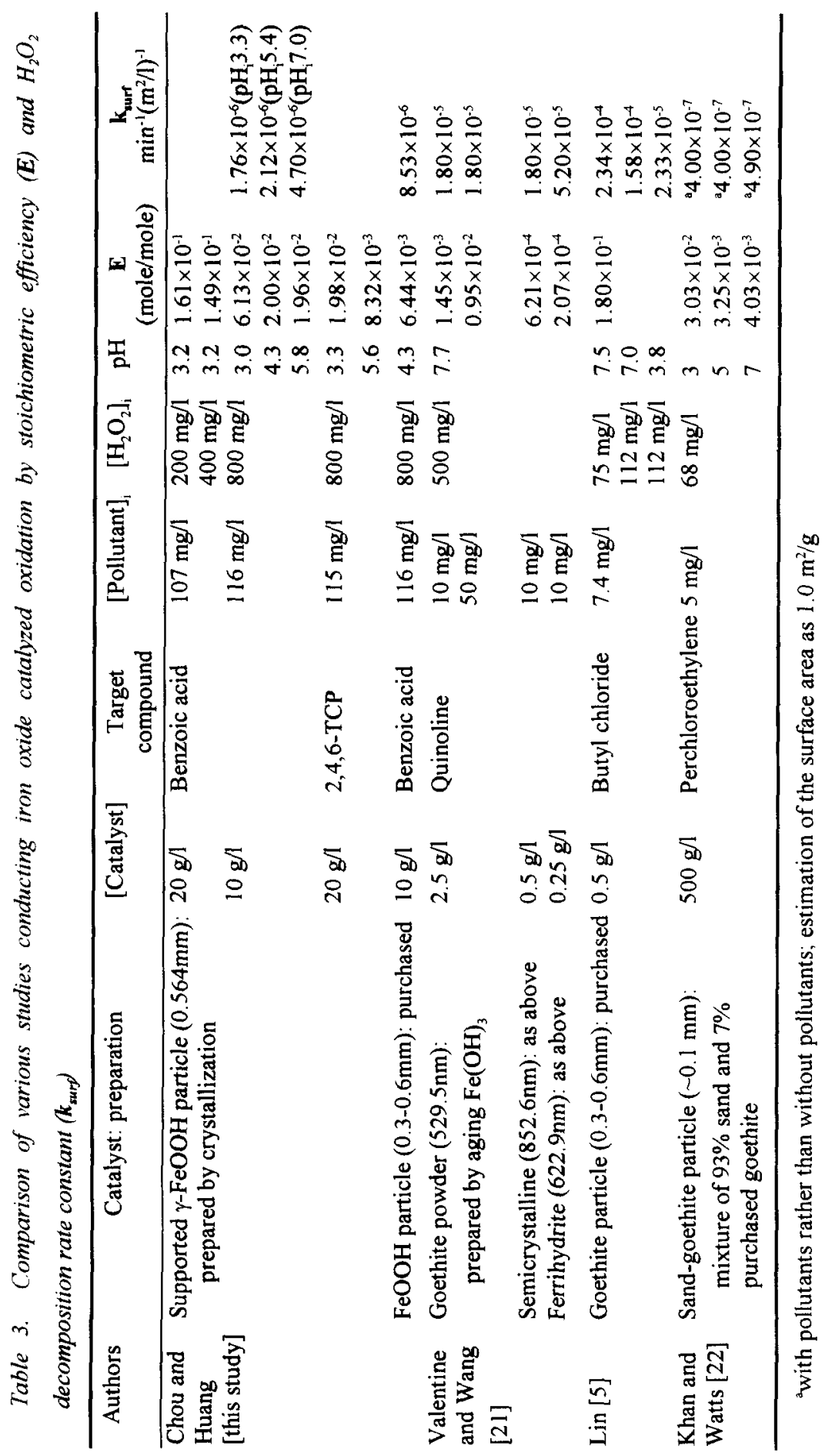


$\mathrm{H}_{2} \mathrm{O}_{2}$ for the $\mathrm{OH}$ radical, and explained by the following reaction:

$$
\mathrm{H}_{2} \mathrm{O}_{2}+\mathrm{OH} \cdot \rightarrow \mathrm{HO}_{2}+\mathrm{H}_{2} \mathrm{O}
$$

where $\mathrm{HO}_{2}$ - is the perhydroxyl radical, which is a relatively weak oxidant compared to the $\mathrm{OH}$. It has been proven that higher $\mathrm{H}_{2} \mathrm{O}_{2}$ concentration favors the above mechanism (24).

\subsection{Extent of heterogeneous catalysis and homogeneous catalysis}

To thoroughly understand the proportions of heterogeneous catalysis and homogeneous catalysis, a parallel oxidation reaction was conducted with an equivalent concentration of soluble ferrous ion. The experiments were carried out by adding $5 \mathrm{mg}-\mathrm{Fe} / \mathrm{l}$ (as $\mathrm{FeSO}_{4}$ ) and $800 \mathrm{mg} / \mathrm{H}_{2} \mathrm{O}_{2}$ in the presence (catalyst/Fe(II), trial I) and absence (Fe(II)-only, trial II) of the granular catalyst. The catalyst-only system (trial III) contains $20 \mathrm{~g} / \mathrm{l}$ of catalyst without addition of Fe(II). Table 4 summaries the oxidation and the mineralization of benzoic acid in the above three systems. This table shows that no benzoic acid was left in trial I and II after 1.5 hours, but benzoic acid is depleted till 4.5 hours in trial III. The remaining DOC percentages of trial III and trial II at 5 hours were $41.3 \%$ and $72.9 \%$, respectively. The results demonstrate that trial III has lower benzoic acid oxidation rate but higher mineralization rate than that in trial II, even when the dissolved iron concentration was kept below $5 \mathrm{mg} / \mathrm{l}$. The finding indicates that by-products of benzoic acid oxidation of this Fenton-like reaction $\left(\mathrm{H}_{2} \mathrm{O}_{2}+\gamma\right.$-FeOOH) may be different from those of Fenton's reaction $\left(\mathrm{H}_{2} \mathrm{O}_{2}+\mathrm{Fe}^{2+}\right)$. In other words, they have different mechanisms for benzoic acid oxidation.

A control trial (trial IV) was performed by only adding benzoic acid and catalyst to investigate the adsorption extent. The changes of residual DOC and the dissolved iron concentration during benzoic acid degradation of trials I, II, III, and IV are presented in Figures $4 \mathrm{a}$ and $4 \mathrm{~b}$, respectively. We divide the graph into two regions for the purpose of discussion. The line chosen to separate the two regions is drawn according to the dissolved iron concentration of trial $\mathrm{I}$; the dissolved iron concentration before the line (region $\mathrm{A}$ ) is less than $5 \mathrm{mg} / \mathrm{l}$ because of adsorption effect on $\gamma-\mathrm{FeOOH}$, and after the line (region $\mathrm{B}$ ), larger than $5 \mathrm{mg} / \mathrm{l}$. At 2.3 hours of reaction, the dissolved iron concentration of trial I approaches that of trial II; the remaining DOC percentages of trial I, II, and IV are $67.7 \%, 91.8 \%$, and $99 \%$, respectively (Figure $4 \mathrm{a}$ ). This means $31.3 \%$ of DOC removal was due to the combined effect of heterogeneous and homogeneous catalysis (trial I), while only $7.2 \%$ of DOC removal was attributed to homogeneous catalysis alone (trial II). Therefore, about $77 \%$ of mineralization is contributed by heterogeneous catalysis within region $\mathrm{A}$, where heterogeneous catalysis dominates. Khan and Watts (22) also found the similar phenomena using the silica sand-goethite catalyst and $\mathrm{H}_{2} \mathrm{O}_{2}$ to treat percholoroethylene (PCE). They proved that up to $94 \%$ of PCE degradation was attributed to heterogeneous catalysis within the first 24 hours at $\mathrm{pH} 3$, where slight homogeneous catalysis by soluble iron occurred. In region B, benzoic acid was completely oxidized to its by-products. The dissolved iron concentration of trial I was higher than that of trial II; the difference increased gradually due to $\mathrm{Fe}^{2+}$ dissolution from $\gamma$-FeOOH. Therefore, we can conclude that homogeneous 
catalysis is of increasing importance in region B of the heterogeneous system.

Table 4. Oxidation and mineralization of benzoic acid in trials $I, I I$, and III

\begin{tabular}{lccc}
\hline \multicolumn{1}{c}{ Trial } & $\begin{array}{c}\text { BA depletion } \\
\text { (h) }\end{array}$ & $\begin{array}{c}\text { DOC }_{5 \mathrm{~h}^{\mathrm{a}}} \\
(\%)\end{array}$ & $\begin{array}{c}\text { Soluble Fe }_{5 \mathrm{~h}} \\
(\mathrm{mg} / \mathrm{l})\end{array}$ \\
\hline I: catalyst/Fe(II) system & 1.5 & 39.4 & 10.4 \\
II: Fe(II)-only system & 1.5 & 72.9 & 5 \\
III: catalyst-only system & 4.5 & 41.3 & 2.3 \\
\hline
\end{tabular}

${ }^{\mathrm{a}} \mathrm{DOC}{ }_{5 \mathrm{~h}}$ : the remaining DOC percentage at 5 hours of reaction

$\mathrm{Fe}(\mathrm{II})$ dosage $=5 \mathrm{mg}-\mathrm{Fe} / \mathrm{l}, \mathrm{pHi}=3.2,[\mathrm{BA}]_{i}=107 \mathrm{mg} / \mathrm{l}_{2}\left[\mathrm{H}_{2} \mathrm{O}_{2}\right]_{i}=800 \mathrm{mg} / \mathrm{l}, \mathrm{DOC}_{\mathrm{i}}=95.5 \mathrm{mg} / \mathrm{l}$.

Trial I -- catalyst/Fe(II) system: with $20 \mathrm{~g} / \mathrm{l}$ of catalyst and with $5 \mathrm{mg}-\mathrm{Fe}(\mathrm{II}) / 1$

Trial II -- Fe(II)-only system: without catalyst and with $5 \mathrm{mg}-\mathrm{Fe}(\mathrm{II}) / 1$

Trial III - catalyst-only system: with $20 \mathrm{~g} / \mathrm{l}$ of catalyst and without $\mathrm{Fe}$ (II)
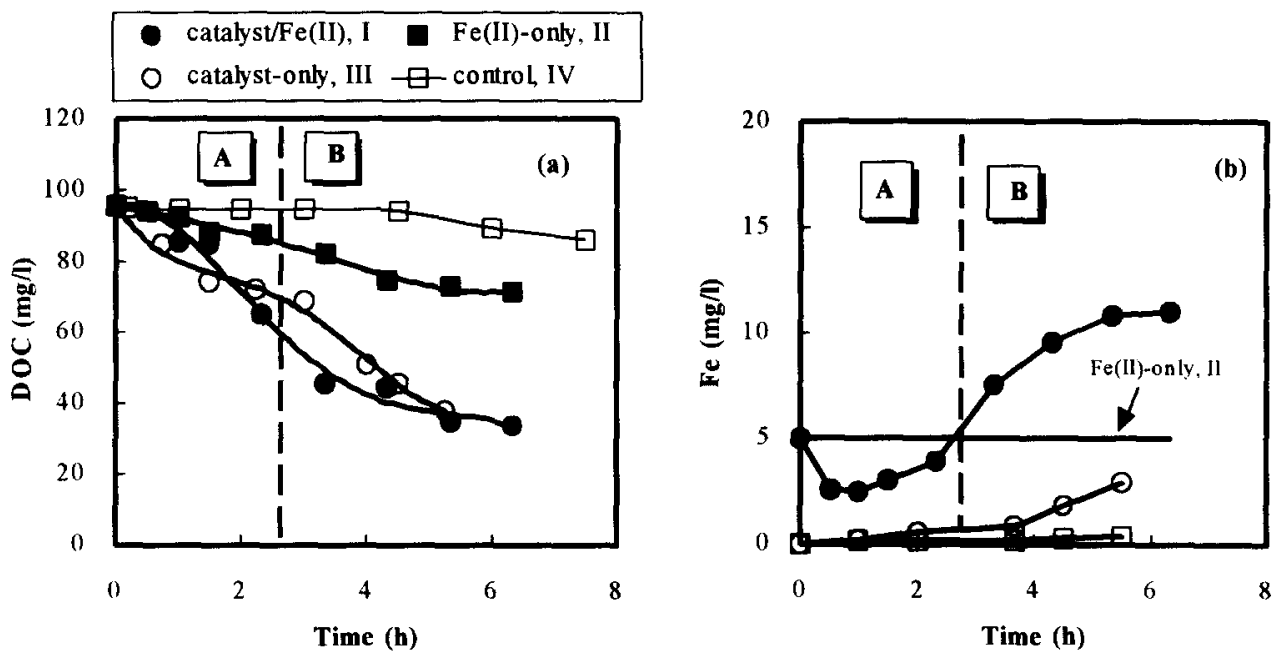

Figure 4. (hanges of (a) residual DOC, and (b) dissolved iron concentration during oxidation of benzoic acid in trials $I, I I, I I I$, and $I V$. The experimental conditions of trials $I, I I$, and III are the same as those in Table 4. The control system (trial $\mathrm{V}$ ) contains only benzoic acid and $20 \mathrm{~g} / \mathrm{l}$ of catalyst (without $\mathrm{H}_{2} \mathrm{O}_{2}$ ).

\section{CONCLUSIONS}

According to the above results and discussion, we have the following conclusions:

(1) The novel catalyst prepared by our crystallization process has been identified as $\gamma$-FeOOH coated onto brick grains, and it has the ability to decompose hydrogen peroxide as well as degrade benzoic acid. The supported $\gamma$-FeOOH catalyst has been proven to possess lower reactivity toward $\mathrm{H}_{2} \mathrm{O}_{2}\left(\mathrm{k}_{\text {surf }}\right)$ but higher stoichiometric efficiency $(\mathrm{E})$ in oxidizing benzoic acid than goethite, a promising catalyst. 
(2) In the absence of benzoic acid, hydrogen peroxide is decomposed primarily on the catalyst surface. The decomposition rate follows a first-order kinetics and appears to increase as $\mathrm{pH}$ increases in this heterogeneous catalysis system.

(3) In the presence of benzoic acid, the majority of mineralization of benzoic acid takes place on the catalyst surface through heterogeneous catalysis in the early stage, while some occur in the aqueous phase through homogeneous catalysis. Heterogeneous catalysis in the presence of benzoic acid apparently dissolves more iron than that in the absence of benzoic acid, and the iron concentration is increased by increasing $\mathrm{H}_{2} \mathrm{O}_{2}$ dosages only in the presence of benzoic acid. These results, we suggest, are attributable to the reductive dissolution reaction of $\gamma$-FeOOH. Oxidation of benzoic acid in the heterogeneous system contributes electrons to hasten the $\mathrm{Fe}^{2+}$ dissolution of $\gamma$-FeOOH under acidic conditions, thus inducing homogeneous catalytic oxidation.

\section{ACKNOWLEDGMENTS}

The authors would like to thank Dr. Y.H. Huang of the Union Chemical Laboratories of ITRI and Dr. J.R. Pan of Chiao Tung University for their helpful discussions, as well as Miss C. S. Wang for her technical assistance. Furthermore, we would also like to thank Professor H. H. Wei and Ms. S. F. Huang, Department of Chemistry, Tamkang University, for their instructions in and assistance with the Mössbauer spectrum analysis.

\section{REFERENCES}

1. C. Walling, Fenton's reagent revisited, Accounts Chem. Res. 8, 125-131 (1975).

2. L. K. Ewa, Degradation of aqueous nitrophenols and nitrobenzene by means of the Fenton reaction, Chemosphere 22, 529-536 (1991).

3. D. L. Sedlak and A. W. Andren, Oxidation of chlorobenzene with Fenton's reagent, Environ. Sci. Technol. 25, 777-782 (1991).

4. C. M. Miller and R. L. Valentine, Hydrogen peroxide decomposition and quinoline degradation in the presence of aquifer material, Water Res. 29, 2353-2359 (1995).

5. S. S. Lin, Interaction of $\mathrm{H}_{2} \mathrm{O}_{2}$ with iron oxide for oxidation of organic compounds in water, $\mathrm{Ph} . \mathrm{D}$. Thesis, Drexel Univ., Philadelphia (1996).

6. J. Parker, Research produces breakthrough in aromatic chemical treatment, Industrial Waste Management 5, 17-18 (1994).

7. N. Al-Hayek and M. Dore, Oxidation of phenols in water by hydrogen peroxide on alumina supported iron, Water Res. 24, 973-982 (1990).

8. J. E. Atwater, J. R. Akse, J. A. McKinnis and J. O. Thompson, Aqueous phase heterogeneous catalytic oxidation of trichloroethylene, Appl. Catal. B: Environ. 11, L11-L18 (1996).

9. Y. H. Huang, G. H. Huang, S. Chou, H. S. You and S. H. Perng, Process for chemically oxidizing 
wastewater with reduced sludge production, A pending ROC patent: 87106787 (1998).

10. A. Vertes and I. Czako-Nagy, Mössbauer Spectroscopy and its application to corrosion studies, Electrochimica Acta 34, 721-758 (1989).

11. P. S. Braterman, A. G. Cairns-Smith and R. W. Sloper, Photo-oxidation of iron(II) in water between pH 7.5 and 4.0, J. Chem. Soc. Dalton Trans., 1441-1445 (1984).

12. D. L. Pardieck, E. J. Bouwer and A. T. Stone, Hydrogen peroxide use to increase oxidant capacity for in situ bioremediation of contaminated soils and aquifers: A review, J. Contam. Hydrol. 9, 221-242 (1992).

13. N. Kitajima, S. Fukuzumi and Y. Ono, Formation of superoxide ion during the decomposition of hydrogen peroxide on supported metal oxides. J. Phys. Chem. 82, 1505-1509 (1978).

14. W. Stumm and J. J. Morgan, Aquatic Chemistry (2nd ed.), Wiley-Interscience, New York (1996).

15. W. Stumm and B. Sulzberger, The cycling of iron in natural environments: Considerations based on laboratory studies of heterogeneous redox processes, Geochim. Cosmochim. Acta 56, 3233-3257 (1992).

16. J. G. Wallace, Hydrogen Peroxide in Organic Chemistry, E. I. du Pont de Nemours \& Co., Wilmington, Delaware (1975).

17. O. K. Borggaard, Effect of surface area and mineralogy of iron oxides on their surface charge and anion-adsorption properties, Clays Clay Miner. 31, 230-232 (1983).

18. M. A. Ali and D. A. Dzombak, Competitive sorption of simple organic acids and sulfate on goethite, Environ. Sci. Technol. 30, 1061-1071 (1996).

19. B. Gu, J. Schmitt, Z. Chen, L. Liang and J. F. McCarthy, Adsorption and desorption of natural organic matter on iron oxide: Mechanisms and models, Environ. Sci. Technol. 28, 38-46 (1994).

20. A. T. Stone, Reductive dissolution of manganese (III/IV) oxides by substituted phenols, Environ. Sci. Technol. 21, 979-988 (1987)

21. R. L. Valentine and H. C. A. Wang, Iron oxide surface catalyzed oxidation of quinoline by hydrogen peroxide, J. Environ. Eng. 124, 31-38 (1998).

22. M. A. J. Khan and R. J. Watts, Mineral-catalyzed peroxidation of tetrachloroethylene, Water, Air, and Soil Poll. 88, 247-260 (1996).

23. D. A. Dzombak and F. M. M. Morel, Surface complexation modeling: Hydrous ferric oxide, John Wiley \& Sons Inc., New York (1990)

24. W. G. Barb, J. H. Baxendale and K. R. Hargrave, Reactions of ferrous and ferric ions with hydrogen peroxide, J. Chem. Soc. 121, $462-470$ (1950). 